\title{
El último aniversario en armas de las FARC-EP en Colinas - Guaviare*
}

\section{The last anniversary in arms of the FARC-EP in Colinas - Guaviare}

\author{
JuAN SEBASTIÁN-FLÓREZ** \\ LINA GABRIELA-CORTÉS***
}

\begin{abstract}
Resumen
Objetivo. El presente artículo analiza los discursos de la guerrilla de las FARC-EP en torno a la conmemoración de su último aniversario en armas, la cual tuvo lugar entre el 27 y el 28 de mayo de 2017 en la antigua Zona Veredal de Transición y Normalización (ZVTN) de Colinas (Guaviare). Metodología. Se hizo observación participante durante la conmemoración y análisis documental de los comunicados públicos que dicha organización presentó en los últimos años alrededor de este aniversario. Resultados. Los discursos que circularon sobre este último aniversario permiten comprender la auto-representación de la conmemoración como parte de unas memorias rebeldes sin armas y las tensiones con discursos oficiales sobre el papel de esta guerrilla en la historia del país. Conclusión. Se plantea que la guerrilla de las FARC-EP intentó articular a través de estas memorias un relato propio sobre la paz que entra en tensión con las formas predominantes como ha sido representada esta organización.
\end{abstract}

Palabras clave: conmemoración, memorias, FARC-EP, FARC, Guaviare, proceso de paz, lucha armada.

\begin{abstract}
Objective: This article analyzes the speeches of the FARC-EP guerrillas around the commemoration of their last anniversary in arms which took place between the $27^{\text {th }}$ and the $28^{\text {th }}$ of May, 2017 in the former Transition and Normalization Rural Zone (TNRZ) of Colinas (Guaviare). Methodology: Participant Observation during the commemoration and documentary analysis of the public statements that the organization presented in recent years about this anniversary were carried out. Results: The speeches spread about the last anniversary allow understanding the self-representation of the commemoration as part of unarmed rebel memories and the tension with the official speeches about the role of this guerrilla in the history of the country. Conclusions: Through these memories, the FARC-EP guerrillas tried to articulate their own account of peace that comes into tension with the predominant ways in which this organization has been represented
\end{abstract}

Key words: commemoration, memories, FARC-EP, FARC, Guaviare, peace process, armed struggle.

\footnotetext{
* Este artículo es resultado de un proyecto financiando por la Pontificia Universidad Javeriana (ID 8318) y titulado Memorias rebeldes. Historias de vida más allá de la guerra en Zonas Veredales Transitorias de Normalización. El proyecto fue desarrollado por el Semillero de Estudios sobre Memoria y Conflicto (Semyc) adscrito a la Facultad de Ciencias Sociales de la Pontificia Universidad Javeriana y coordinado por el profesor Jefferson Jaramillo Marín del departamento de Sociología. En distintos momentos del proceso investigativo participaron, además de los dos autores del presente artículo, los siguientes jóvenes investigadores: Johanna Paola Torres, Diego Fajardo, Luis Fernando Gómez, Diana Salamanca, Sebastian Torres, Marcos Daza, Natalia Londoño, Laura Valencia y Alejandra García.

** Universidad Nacional de Colombia. Bogotá, Colombia. E-mail: jsflorezh@unal.edu.co

(D) orcid.org/0000-0002-6968-6042 Google Scholar

*** Pontificia Universidad Javeriana. Bogotá, Colombia. E-mail: cortes.lina@javeriana.edu.co

(D) orcid.org/0000-0002-9304-6264 Google Scholar
} 


\section{Introducción}

Entre 2012 y 2017, Colombia vivió uno de los momentos más importantes de su historia contemporánea: el proceso de paz entre el gobierno de Juan Manuel Santos y las FARC$\mathrm{EP}^{1}$. Aunque no fue el escenario transicional "perfecto", si permitió un marco de oportunidad político y social para cerrar una larga confrontación armada sin un claro horizonte de solución. Al mismo tiempo, favoreció la diversificación e imaginación social de discursos públicos en torno a la paz, estigmatizados entre 2002 y 2008 por la Política de Seguridad Democrática. Desde la firma del acuerdo final al término del 2017, este proceso enfrentó no pocas crisis; algunas de ellas producto de los incumplimientos o demoras en la implementación de las medidas acordadas por parte de la administración Santos y, otras, resultado de la victoria de Iván Duque en las presidenciales del 2018, dado que esta administración ha cuestionado y lentificado la estructura misma de lo pactado.

En ese escenario, el nuevo partido de la FARC busca desplegar una nueva forma de hacer política basada en una acción pública - no armada. Esta opción por lo nuevo dialoga y entra en fricción con lo viejo, de tal manera que los distintos repertorios y discursos a partir de los cuales el nuevo partido desarrolla esta acción guardan conexión con las maneras históricas como se ha narrado a sí misma esta guerrilla. Esa fricción y diálogo entre lo nuevo y lo viejo plantea preguntas en torno a la memoria organizativa de la propia FARC-EP.

Mientras ocurre una ampliación de la interlocución entre la academia y esta organización en la esfera de la legalidad político-institucional, se experimenta una agudización de las prácticas de asesinato, persecución y estigmatización de la oposición política en el país. Inevitablemente esto nos remite a las construcciones simbólicas con las que se ha definido históricamente la imagen pública sobre las FARC.

El miedo ha sido una de las emociones públicas dominantes frente a las FARC-EP en las dos últimas décadas. Siguiendo a Sandoval (2002) consideramos que "si el temor es efectivamente condición y fundamento de toda sociedad, también se hace inevitable reconocer en él un instrumento específico de la política y el poder" (p.59). Y fue precisamente el miedo a ellas, construido por diversas derechas del país, lo que movilizó también el odio con esta organización y en gran medida lo que constituye una de las matrices que orientan los discursos guerreristas en el país.

Pese a la capitalización política de nuevos enemigos y nuevos miedos en el país (v.g el ELN, la Venezuela de Maduro, Petro-Presidente, el populismo de la izquierda, la movilización

\footnotetext{
${ }^{1}$ Con motivo del tránsito de una organización política armada a un partido político legal se utiliza en adelante el nombre FARC en las situaciones en las que se haga referencia al nuevo partido. En las situaciones anteriores a la fundación del partido se le nombrará FARC-EP.
} 
social), la configuración de la FARC como partido ha logrado reducir o atenuar relativamente esta simbología, al menos las caracterizaciones "monstruosas" que circularon como moneda corriente en los medios de comunicación masiva. Tanto para la FARC, que en la construcción de su referencia pública busca tomar distancia relativa del pasado en armas y consolidarse como un partido político legal, como para quienes actúan en detrimento de los acuerdos y no distinguen entre el actual partido, la antigua guerrilla o las disidencias, la enunciación del pasado, la administración de narrativas y las distintas formas de representación y autorepresentación son escenarios de mucha disputa.

El artículo analiza la auto-representación de la conmemoración de los 53 años de fundación de las FARC-EP que tuvo lugar en la antigua Zona Veredal de Transición y Normalización (ZVTN) de Colinas, en el departamento del Guaviare, durante los días 27 y 28 de mayo de 2017. La intención del artículo es comprender cómo esta conmemoración es enmarcada dentro de lo que se denomina en este artículo "memorias rebeldes sin armas" y analizar las tensiones derivadas de los discursos oficiales sobre el papel de esta guerrilla en el país.

El artículo se nutre de un enfoque metodológico cualitativo, que de forma combinada hizo uso de la observación participante durante los dos días de conmemoración, con análisis documental sobre los comunicados públicos que dicha organización presentó en los últimos años sobre la conmemoración de esta fecha. Al momento de la investigación en el ETCR de Colinas, vivían cerca de 400 excombatientes de las FARC-EP, liderados por Noé Gutiérrez Galvis, el comandante "Ardillo", quien sustituyó en el mando al comandante Iván Alí y que según los medios oficiales estaría dentro de "los disidentes".

\section{Discusión}

\section{La conmemoración como espacio de tensión y como momento de ruptura}

Nuestra opción analítica son las memorias en plural. Este punto de arranque, ampliamente aceptado en el campo de los estudios sobre la memoria asume que no existe socialmente una memoria en singular, sino diferentes memorias colectivas e individuales, culturales y biográficas, públicas y privadas, así como diferentes usos y abusos de las mismas (Blair, 2011; Jelin, 2001; Rufer, 2010). Es decir, las memorias son parte de un proceso intersubjetivo mediante el cual diversos sujetos asignan, marcan y despliegan sentidos sobre el pasado o los pasados en distintos momentos del presente.

Las memorias se activan, construyen y administran a través de prácticas simbólicas y materiales alrededor de las cuales hay disputas y negociaciones (Jaramillo, Parrado y Torres, 2017). Una de estas prácticas son las conmemoraciones que devienen en espacios privilegiados para abordar las tensiones y los momentos de ruptura con el pasado y con el presente de una organización como las FARC-EP con la celebración de su aniversario 53. 
En torno a las conmemoraciones retomamos dos aproximaciones, la de Elizabeth Jelin (2001) y la de Steve Stern (2000). Para Jelin (2001), las conmemoraciones son momentos y espacios privilegiados para reconocer las tensiones que están presentes en las prácticas dominantes y resistentes de memoria y sus efectos en las identidades. Esta autora sugiere que las memorias generan, articulan, crean y transforman sentidos. Stern (2000), considera que las conmemoraciones tienen la intención de posicionar y promocionar unos discursos socialmente significativos en unas coyunturas específicas. En estos casos, las memorias "importan más si se refieren a un momento de ruptura o de viraje profundo, es decir, si son fundadoras de lo que viene después"(Stern, 2000, p. 18).

Para comprender la relación entre tensión y ruptura en las conmemoraciones, utilizamos como pretexto analítico y empírico el aniversario número 53 de las FARC-EP. En ella se articulan y configuran muchos ingredientes, como veremos a continuación. De una parte, su historia pasada como organización y el recuerdo siempre presente de Marquetalia, que es a la vez un recuerdo que se resignifica cada vez que se enuncia. De otra parte, su presente de tránsito como organización en armas a un partido político sin ellas, pero también las formas en cómo es etiquetada y nombrada por la institucionalidad y las fricciones que esto desencadena; y, por supuesto, su futuro incierto, especialmente para la guerrillerada, en un país y con unas élites acostumbradas a incumplir lo pactado.

Iniciaremos el trayecto mostrando el valor como acontecimiento que tiene Marquetalia para las FARC-EP; luego señalaremos las características y particularidades de la conmemoración del 27 y 28 de mayo en la antigua zona veredal, especialmente lo referido a los distintos discursos y narrativas que circularon y se posicionaron desde la misma sobre la organización, la paz y la opción revolucionaria con armas y sin armas

\section{Marquetalia: acontecimiento fundacional y de disputa}

El 27 de mayo de 1964 se llevó a cabo una operación militar en contra de la insurgencia en el sur del departamento del Tolima, ordenada por el segundo gobierno frente-nacionalista de Guillermo León Valencia y liderada por el coronel José Joaquín Matallana y el comandante de la VI Brigada, coronel Hernando Currea Cubides. La envergadura de la operación ha sido motivo de discusión, dado que se coloca en cuestión la "cifra emblematizada" de 16.000 hombres de fuerzas combinadas del ejército que hicieron parte de ella: infantería, artillería, aviación para bombardeos y aerotransporte (Arenas, 2015; Marulanda, 2015).

Este acontecimiento hace "parte integral" del mito fundacional de las FARC-EP como insurgencia moderna, con implicaciones simbólicas para el desenvolvimiento de la historia del conflicto político, social y armado en el país (Ferro y Uribe, 2002; Uribe, 2007). Una de las justificaciones estatales para la operación fue que varios asentamientos campesinos en esta región eran o habían devenido en "Repúblicas Independientes”, en símbolos de la subversión comunista. A la luz de los planteamientos de la Doctrina de Seguridad Nacional, las operaciones 
militares sobre esta área se justificaban por cuanto iban a restituir la soberanía y a limpiar el nombre de la democracia

Aunque la fundación de las FARC-EP se fijó el 27 de mayo de 1964, la elección de esta fecha tiene que ver más con las "múltiples génesis" de su experiencia armada que con un momento específico de constitución como organización. Antes de Marquetalia pasó la experiencia del Davis en 1958 donde, según Marulanda (2015) y Arenas (2015) el movimiento campesino adoptó una disciplina militar. También es importante señalar que en 1965 se desarolló la primera conferencia guerrilera y en 1966 se adoptó el nombre de FARC (Medina, 1986).

Aunque los guerrilleros que estuvieron en los bombardeos y enfrentamientos de Marquetalia, no se identificaron en comienzo con el nombre de FARC, este acontecimiento, considerado el momento fundacional de dicha organización, permite entrever el carácter selectivo y político de la memoria. Al definir el 27 de mayo como fecha para conmemorar el surgimiento de la organización se puede argumentar, siguiendo a Portelli (1989), que "más que el propio acontecimiento en sí, lo significativo es la memoria de este acontecimiento" (p. 30). ¿Por qué se eligió esta fecha y no otra? ¿Por qué no se escogió un momento anterior para conmemorar, si las guerrillas del sur del Tolima tenían antecedentes de coordinación conjunta? ¿Por qué no se fijó en la primera o segunda conferencia donde las FARC adoptaron el Programa Agrario? Si bien un abordaje profundo de estas preguntas exige una indagación sobre la trazabilidad histórica de esta conmemoración que supera este artículo, ciertas características de la conmemoración número 53 aportan elementos de perspectiva, y permiten adentrarse en los usos políticos de esta decisión, tal y como lo mostraremos más adelante.

Ahora bien, para las FARC-EP, Marquetalia se constituyó en una "marca de inicio" de una plataforma organizativa. Esta marca estuvo acompasada de otros hitos centrales como, por ejemplo, "el Programa Agrario de los Guerrilleros", que va a ser clave para la defensa de "la vía revolucionaria armada" como "su única alternativa”. De hecho, así lo reconoció el escritor Arturo Alape en los años noventa en uno de sus más reconocidos libros y que tenía por protagonista a Manuel Marulanda Vélez; allí, Alape destaca el siguiente fragmento del Programa Agrario de los Guerrilleros:

Nosotros somos revolucionarios que luchamos por un cambio de régimen. Pero queríamos y luchábamos por ese cambio usando la vía menos dolorosa para nuestro pueblo: la vía pacífica, la vía democrática de masas. Esa vía nos fue cerrada violentamente con el pretexto fascista oficial de combatir supuestas 'Repúblicas Independientes', y como somos revolucionarios que de una u otra manera jugaremos el papel histórico que nos corresponde, nos tocó buscar la otra vía: la vía revolucionaria armada para la lucha por el poder. (Alape, 1994, p. 18) 
En esa misma publicación, Manuel Marulanda planteó: "Nosotros no impusimos la violencia. La violencia nos la impusieron a nosotros" (Alape, 1994, p.14). En ambas citas vale la pena destacar dos elementos que abordan sentidos distintos, aunque funcionan de forma articulada. Por un lado, en la cita del Programa Agrario se habla de la opción revolucionaria armada como una vía que "tocó buscar", es decir, de una decisión tomada por la inviabilidad de otras opciones; por otro lado, Marulanda plantea una narrativa de la violencia como una imposición de otros, no como una decisión propia. Más adelante se profundizará en algunos elementos en torno a los significados puestos en juego en estos casos; empero, el punto que queremos destacar, por el momento, es que en ambos casos, así como en otros relatos sobre el origen de las FARC - EP, el 27 de mayo de 1964 se define como la referencia geográfica, temporal y simbólica que permite articular tres cuestiones sustantivas: a. La enunciación del inicio de una guerra impuesta por otros; b. La resistencia político armada propia; y, c. Un discurso que fue "caballito de batalla" de la organización: el de la lucha por "la paz que le robaron a Colombia los negociantes y politiqueros" (CEDEMA, 2013).

\section{La conmemoración del 27 y el 28 de mayo: contrapunteo discursivo}

La conmemoración no. 53 ocurrida entre el 27 y el 28 de mayo de 2017, fue distinta a todas las anteriores para las FARC-EP. El contexto de tránsito de la organización a la legalidad permitió que tuviera un carácter público y se divulgará en distintos medios. Este aniversario no fue solo una celebración más, sino un "momento y espacio privilegiado", siguiendo la observación de Jelin, que revela el contrapunteo entre dos promotores de visiones distintas sobre lo que ha ocurrido en el contexto nacional con las FARC, a raíz del proceso de firma del Acuerdo Final de Paz.

De una parte, la visión institucional y la opinión general leyeron el evento conmemorativo como "el último aniversario en armas" de una organización que producto de un acuerdo de paz "transitaba indefectiblemente" hacia la legalidad. De otra parte, el propio sentir de "los y las farianas" quienes, dentro del mismo contexto de celebración, y ante la reiterada etiqueta enunciativa institucional como "excombatientes", manifestaban que ellos seguían siendo combatientes, solo que ahora lo eran sin armas.

El título escogido para el comunicado de promoción de la celebración fue el siguiente: "53 años de lucha por la paz”. El mismo se acompañó de consignas en la antigua Zona Veredal de Colinas que planteaban: "Desde Marquetalia hasta la Paz con justicia social". Este tipo de enunciados hablan de una organización que, si bien era consciente del tránsito que estaba viviendo, seguía asumiéndose como "rebelde, pero sin armas".

En ese mismo comunicado se comienza apelando a la intención de paz que tenían los guerrilleros marquetalianos, señalando: 


\begin{abstract}
Antes del bombardeo y de los desembarcos, Manuel Marulanda Vélez, Jacobo Arenas y sus compañeros tocaron todas las puertas del diálogo para evitar el comienzo de una nueva etapa de guerra en Colombia, pero pudo más la intransigencia local y la intriga del Norte que temía para la América continental la reedición de la experiencia de la Revolución Cubana. (CEDEMA, 2017)
\end{abstract}

De manera adicional, en el citado comunicado de esta conmemoración, la "vocación originaria de paz" de esta guerrilla se sitúa en una dimensión de larga duración al mencionar cuatro intentos de solución política que se constituyen como hitos en su historia organizativa:

Lo intentamos en los Diálogos de La Uribe durante el gobierno de Betancur (...) Luego buscamos la reconciliación en las conversaciones de Caracas y Tlaxcala, esfuerzo que fue ahogado por la apertura democrática, el miserable neoliberalismo que nos robó la esperanza (...) San Vicente del Caguán fue la persistencia del sueño frustrado de paz de las FARC frustrado nuevamente por la perfidia de un mandatario conservador (...) Pero a pesar de las vicisitudes y tocados por el dolor de patria que ha producido esta prolongada confrontación, logramos nuevamente encender la llama de la esperanza con los Diálogos de La Habana donde pudimos por fin rubricar un tratado para la construcción de la paz estable y duradera. (CEDEMA, 2017)

Estos discursos pueden entenderse también en clave de unas promesas de un futuro mejor. Con el proceso de legalización y dejación de armas en ciernes, la conmemoración buscó ser un evento público que recibió en las Zonas Veredales a múltiples delegaciones de espacios urbanos y rurales. En el caso de Colinas estas delegaciones, principalmente, provenían del Guaviare, Arauca y Bogotá. En dicho escenario, las FARC - EP pusieron en escena una serie de narrativas sobre su pasado dirigidas principalmente a impactar en quienes estaban de visita, a partir de un relato nuclear: la historia de las FARC - EP es la historia de su lucha por la paz.

El carácter abierto de la conmemoración fue visto con desconfianza por múltiples sectores y se convirtió en un tema de discusión pública. Entre estas manifestaciones, una de las que mayor eco y polémica despertó fue la carta del general del Ejército Javier Flórez (quien fue parte del equipo negociador en la Habana) dirigida a Sergio Jaramillo (Alto Comisionado para la Paz) dos días antes de la conmemoración. En la carta, el general Flórez señalaba que en este escenario se iban a adelantar un serie de actividades de carácter político y de presión a las comunidades, lo que contraría lo establecido en el acuerdo final (Bejarano, 2017). 
El espacio conmemorativo del 26 y el 27 de mayo de 2017 aportó una perspectiva diferente a la de otros escenarios públicos de amplia atención como la $10^{\text {a }}$ Conferencia de las FARC-EP desarrollada en septiembre de 2016 en los Llanos delYarí. Además, ciertas conmemoraciones de las FARC-EP han buscado constituirse en fechas públicas, desatando una serie de debates y tensiones en torno a qué debe exaltarse del pasado reciente del país y de las memorias rebeldes ${ }^{2}$.

\section{Las conmemoraciones como articuladoras de "relatos de paz"}

En diversos momentos de la historia del país, la paz como relato estuvo presente en la memoria y el discurso público de las FARC-EP ${ }^{3}$. El último aniversario en armas no fue la excepción a esto. No obstante, en esta conmemoración, el relato de la paz articuló e integró discursos sociales, políticos y culturales que venían circulando en otras conmemoraciones

Rastreando los comunicados emitidos en conmemoraciones anteriores encontramos que a partir del año 2013 y hasta el 2017, en los aniversarios 49, 50, 51, 52 y 53, la paz se convierte en el principal eje discursivo. De hecho, cuatro de estos comunicados se titulan con el número de la conmemoración seguido de la frase “...años de lucha por la paz” (CEDEMA, 2013, 2014, 2015, 2016, 2017). Esta centralidad contrasta con comunicados de conmemoraciones anteriores al 2013 donde se destaca en los títulos la presencia de "significantes" como batalla, resistencia armada y lucha armada (CEDEMA, 2010, 2011, 2012). Este desplazamiento hermenéutico coincide con el momento de inicio de la fase pública de los diálogos de paz entre la guerrilla y el gobierno de Juan Manuel Santos hacia septiembre del 2012, cuando se puso fin a una fase de diálogos exploratorios desarrollados en secreto entre las partes desde 2011.

La centralidad del relato de la paz implica tensiones y resonancias con otros dos significantes que de diferentes formas hacen parte de la propia construcción narrativa de esta organización: la guerra y la lucha armada. La guerra fue un significante históricamente dotado de sentidos negativos por parte de las FARC - EP. El comunicado público de la conmemoración de los 53 años se refiere a esta como "el fango de la guerra" (CEDEMA, 2017). En la misma dirección, en la conmemoración del 2012 se propuso que "la guerra, toda guerra, consiste en un enfrentamiento desatado por los ricos en contra de los pobres (...) La guerra incluye entonces el silencio y la mentira” (CEDEMA, 2012). Estos sentidos permiten a las FARC definir la guerra como "una imposición”, como "una acción que es ajena”, que en su caso "tiene origen en el bombardeo a los marquetalianos".

\footnotetext{
${ }^{2}$ Un ejemplo de ello fue la conmemoración realizada con motivo de la muerte de Jorge Briceño, a manos del Estado, uno los "iconos de lucha" de esta organización.

${ }^{3}$ En una reciente investigación del historiador Robert Karl (2018) se evidencia cómo las figuras de Alberto Lleras Camargo y Manuel Marulanda hicieron aportes en las búsquedas locales, regionales y nacionales de "paz criolla" en los años 50 y 60.
} 
El significante lucha armada, por su parte, permite narrar la violencia ejercida por los guerrilleros "como una resistencia frente a la forma de guerra impuesta". Al conmemorar los 48 años de su aniversario en el comunicado de mayo de 2012 se plantea, por ejemplo "a los 48 años de lucha armada rebelde, reiteramos al pueblo de Colombia nuestro juramento de vencer (CEDEMA, 2012). Incluso, en este mismo comunicado, a escasos meses del anuncio de la fase pública de los diálogos, se legitimaba este tipo de alzamientos armados al plantear que la hostilidad de la fuerza pública y los crímenes contra el movimiento Marcha Patriótica: "[ponían] de presente la ruindad de la democracia colombiana y la vigencia indiscutible de la lucha armada de su pueblo". Allí mismo, por un lado, se asegura "nunca hemos querido la guerra", y al tiempo señalan que "las FARC-EP somos pueblo que enfrenta con armas las armas del poder y la riqueza”. El entramado simbólico del relato fariano propone de manera dicotómica que mientras la guerra la hacen los ricos, la oligarquía y el imperialismo, la lucha armada es la resistencia de la gente pobre del campo y la ciudad.

Dialogando con ambos significantes - guerra y lucha armada-, el relato de la paz se presenta en la conmemoración número 53 como un proyecto histórico que es, tanto la salida a la guerra impuesta desde 1964 en Marquetalia, como la continuidad de la lucha armada con la que resistieron. Estos tres significantes juntos permiten comprender cómo lucha armada y paz no se presentan contradictorios para las FARC-EP, sino que funcionan de forma integrada, como parte de sus memorias rebeldes.

En un mural realizado en la caseta de comunicaciones de Colinas, el diálogo entre estos significantes se observa con claridad (ilustración 1). Allí, como parte de las iniciativas de conmemoración del natalicio de Manuel Marulanda, se entrelaza un fusil con el número 87 que refiere al aniversario de su nacimiento en 1930, proponiendo de esta forma que su vida estuvo atravesada por su experiencia guerrillera. Esto se acompaña con una imagen de Marulanda junto a la frase: "Hay que buscar una salida de carácter político y no armado - 1986". El tipo de narrativas que proponen "los farianos y las farianas" sobre el fusil y el discurso de la paz sería seguramente interpretado como algo contradictorio. Sin embargo, esta "contradicción” es lo que hace parte del fundamento de esas memorias rebeldes con las que ellos mismos se auto representan. 


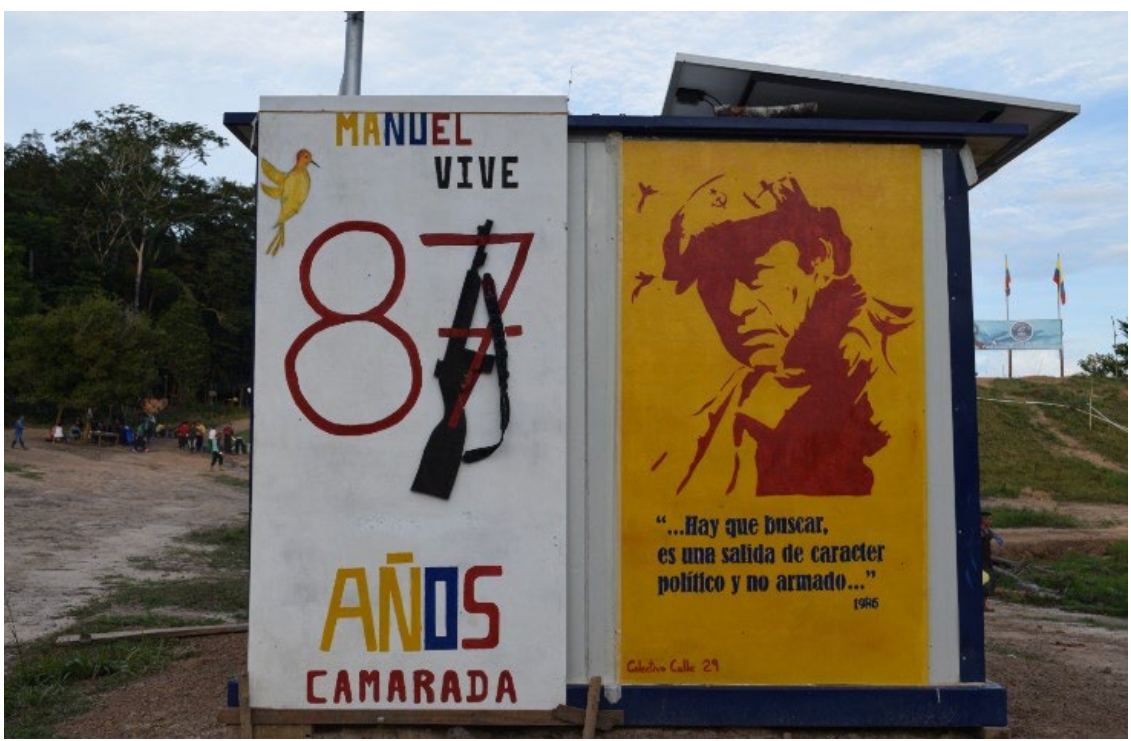

Ilustración 1. [Fotografía de Johana Torres], Colinas, Guaviare, 2017.

Fuente: archivo fotográfico personal.

\section{La conmemoración de 2017 y las memorias rebeldes sin armas}

Durante los dos días de conmemoración del último aniversario en armas de las FARC-EP, uno de los "lugares" protagónicos fue una carpa dedicada a una serie de exposiciones de la organización titulada "Memoria Histórica de las FARC - EP". Al indagar con las personas de la antigua Zona Veredal señalaron que, aunque en el espacio estaba contenido el trabajo de muchas personas, al frente del mismo estuvieron Ingrid y Diomedes.

En la "carpa", como se le llamó al espacio, se presentaron una serie de narrativas sobre la memoria de las FARC-EP a partir de varios registros, entre ellos fotografías, dibujos y una maqueta. La imagen de Manuel Marulanda tuvo centralidad aunque compartida con la figura de Jacobo Arenas. Dado que el 13 de mayo se conmemoraba el natalicio de Marulanda, ambas conmemoraciones tuvieron carpas. Las imágenes expuestas buscaron mostrar a Marulanda, casi siempre en espacios de diálogo con el gobierno y con consignas a favor de la paz.

Como parte de las exposiciones sobresalió una gran galería con unas 30 fotos de Marulanda y, orbitando alrededor de esta figura, una serie de fotos de otros comandantes. Además, estaban expuestos los dibujos de Diomedes hechos a lápiz sobre cartulina blanca. El diálogo entre las conmemoraciones del natalicio de Marulanda y el surgimiento de las FARC - EP tenía la pretensión de querer contar la historia de la guerrilla a partir de la vida de uno de sus principales comandantes. 
La maqueta, que estaba principalmente a cargo de Ingrid, contaba la historia de las FARC-EP desde Marquetalia hasta el actual proceso de paz. Usando la cartografía y la línea de tiempo de forma integrada, a partir de una composición hecha mayoritariamente con papel, pintura y cartulina, se tejió una memoria de la organización guerrillera desde cuatro hitos: a. El bombardeo de Marquetalia; b. El bombardeo a Casa Verde; c. El Proceso de Paz del Caguán; y d. El Proceso de Paz con sede en la Habana. La maqueta contenía un mapa de Cuba y otro de Colombia donde estaban señaladas cada una de las ZVTN, ambos mapas estaban ubicados bajo la famosa foto del apretón de manos entre Santos y Timochenko. El discurso nuclear a todo esto era que las FARC - EP desde su origen habían buscado y anhelado la paz.

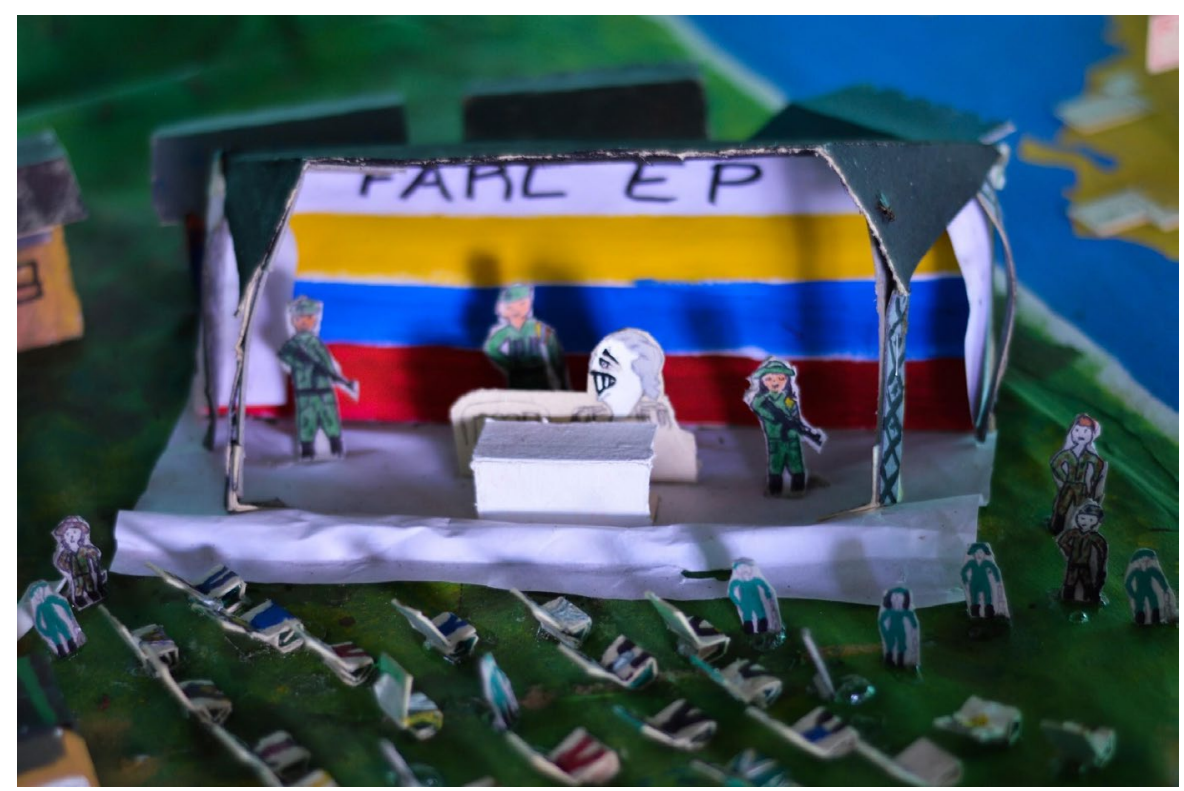

Ilustación 2. [Fotografía de Natalia Londoño]. Colinas, Guaviare, 2017.

Fuente: archivo fotográfico personal. Representación de la silla vacía en la maqueta.

En el ejercicio de observación participante, logramos identificar como un fariano tomó la voz para explicar lo que estaba representado en la maqueta diciendo a un grupo de visitantes que con 5 millones invertidos con los guerrilleros del sur del Tolima se había evitado la guerra, proponiendo además que la organización de estos campesinos fue un proyecto de paz truncado por la Operación Marquetalia. En su relato parecía hacerse evidente la conexión entre las Zonas Veredales y Marquetalia. De hecho, al hablar de las apuestas de autonomía de las colonias campesinas del sur de Tolima se las equiparaba con los proyectos productivos de las Zonas Veredales. En este caso, la manera de contar la propia historia tenía una forma 
cíclica: la guerra impuesta en el sur del Tolima truncó proyectos productivos y de vida, pero nuevos objetivos de poblamiento y producción se proyectan con las ZVTN. En ese relato, lo que se estaba proponiendo era que las posibilidades que no tuvieron los fundadores de su propia organización, ante la negativa del gobierno de invertir " 5 millones de pesos", se podrían conseguir en el presente mediante el proceso de paz.

Al reflexionar sobre la relación entre memoria e identidad, resulta clave volver a Jelin (2002) cuando propone que "el núcleo de toda identificación individual y grupal es la continuidad en el tiempo y el espacio del sentido de pertenencia” (p. 24). En ese sentido el vínculo que establecía el fariano, entre la memoria de Marquetalia con el presente de las Zonas Veredales como Colinas, señalaba su plena identificación con aquellos que fundaron las FARC-EP en 1964.

Esta identificación y continuidad puede verse también en el comunicado que se publicó el mismo 2017 y que rezaba lo siguiente: "Cuánto hubiesen deseado nuestros padres fundadores Manuel Marulanda Vélez y Jacobo Arenas, Alfonso, Raúl, Jorge, Efraín y otros compañeros, protagonizar la realización de este momento histórico de sus sueños” (CEDEMA, 2017). Alrededor de la carpa y la maqueta lo que va a ocurrir es la circulación de "una serie de sentidos que al narrarse se presentaran como una reconstrucción de narrativas ancladas al pasado" (Jelin, 2001, p.24).

El vínculo construido entre la memoria de Marquetalia y las ZVTN no fue una operación exclusiva de las FARC-EP. En una carta de marzo de 2017 dirigida a Juan Manuel Santos por las “altas jerarquías militares en retiro", entre los que se contaban antiguos generales del ejército, la armada y la policía, los firmantes cuestionaron la dinámica de las ZVTN. Para estos firmantes, las zonas veredales conducirían a reeditar las "Repúblicas Independientes". Vale la pena recordar que esta representación fue parte de la narrativa que buscó justificar la operación de bombardeo contra los guerrilleros del sur del Tolima, y el despliegue general a nivel regional de iniciativas militares como la operación LASO (Jaramillo, 2014). En la carta se planteaba a Santos:
(...) queremos expresarle nuestra inquietud por el interés manifiesto de esta organización de crear a toda costa zonas permanentes y no de carácter transitorio en los sitios acordados, para conformar peligrosos asentamientos con grupos no desmovilizados y comunidades afectadas, que potencialmente y hacia el futuro inmediato, se constituirían en graves amenazas y factor de perturbación, tal como aconteció en el pasado con las llamadas 'Repúblicas Independientes', que tanto daño causaron a la integridad territorial de la nación. (Acore, 2017) 


\section{La conmemoración de 2017: los referentes simbólicos}

Durante los días de la conmemoración se destacaron diferentes propuestas artísticas y culturales de grupos provenientes de Bogotá, Arauca y de la misma Zona Veredal. El clima de posacuerdo permitió que muchas personas de estas delegaciones, sobre todo los asistentes citadinos, tuvieran contacto por primera vez con personas pertenecientes a una "guerrilla", y encontraran en la conmemoración formas concretas de aportar. Un dato llamativo, a propósito, estuvo en una de las artistas provenientes de Bogotá que evitó el nombre que comúnmente usa su personaje artístico para presentarse con el nombre de "Paz Estresada".

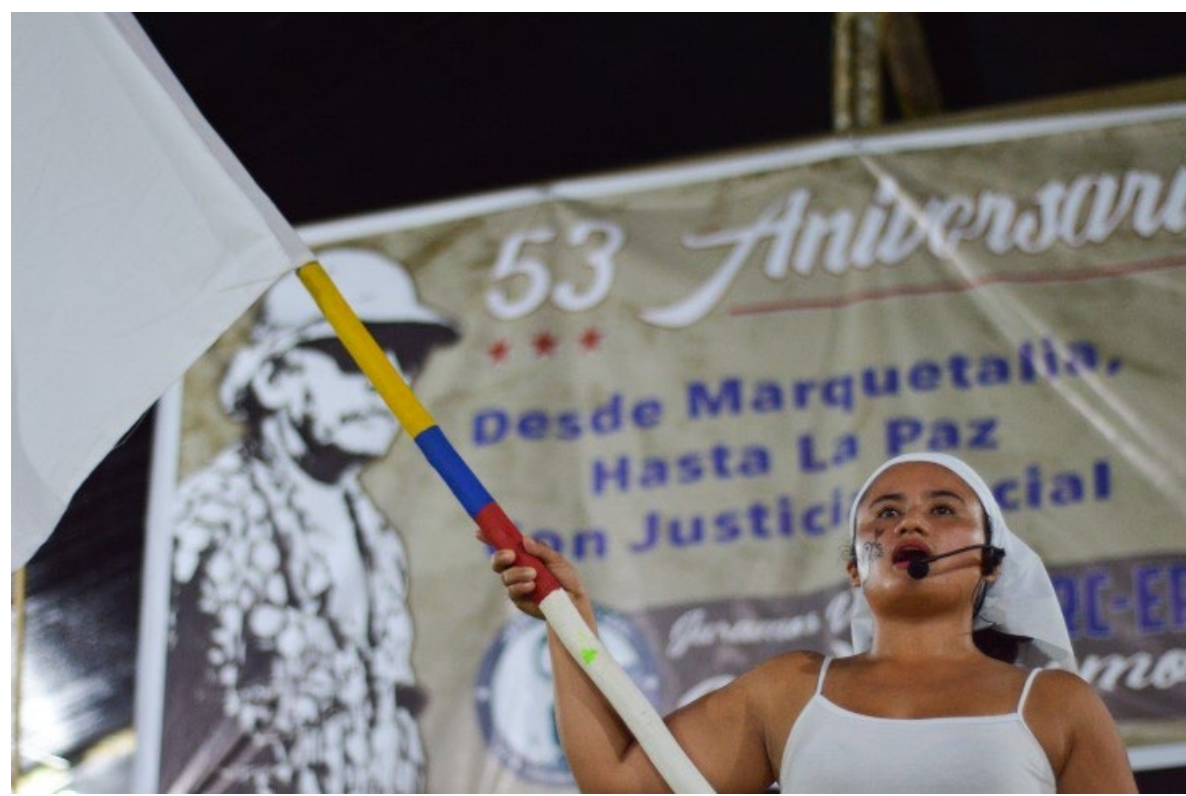

Ilustración 3. [Fotografía de Natalia Londoño]. Colinas, Guaviare, 2017.

Fuente: archivo fotográfico personal. Obra de teatro.

Una de las participaciones más destacadas y llamativas fue la de un grupo de teatro compuesto por combatientes quienes presentaron dos obras. En la primera, participaron cinco mujeres y cuatro hombres, quienes tejieron un relato que de algún modo replicaba lo expuesto en la maqueta antes descrita, aunque con la diferencia que en este caso la historia iniciaba con el bogotazo y no con Marquetalia. La obra circulaba por distintos momentos de la historia guerrillera e integraba relatos personales sobre el ingreso a las FARC - EP, insistiendo particularmente en una idea: no estaban allí ni obligados, ni engañados. Las narrativas de ambas obras estaban encaminadas a presentar el futuro que se estaba abriendo para ellos con el proceso de paz, finalizando con el canto de dos "himnos": el de la alegría y el de la paz. 
Además de estos dos himnos fueron entonados a lo largo de la conmemoración el himno de Colombia, el de las FARC y el de la Internacional Comunista. Los sentidos puestos en escena con estos tres himnos son evidentes, pues atraviesan la identidad de una organización que se define a sí misma como patriota, comunista y antiimperialista.

Al hacer una breve búsqueda en internet, los himnos de la paz y la alegría pueden encontrarse entre cancioneros de iglesias cristianas, pero no entre los que reivindican organizaciones insurgentes. ¿Por qué entonces entonarlos junto a los otros himnos que pueden resultar más afines a la organización? La respuesta e ello creemos encontrarla en algo que ya hemos afirmado en este artículo y es el significado que para las FARC-EP ha tenido la paz como relato nuclear a lo largo de su historia como organización. Junto a los himnos se conjugaron otros referentes simbólicos alusivos a la paz. Tal es caso de la paloma y la bandera que compartió espacio con el corazón compuesto de manos entrelazadas y la rosa, desplazando al fusil y su lugar protagónico en la vida de la organización.

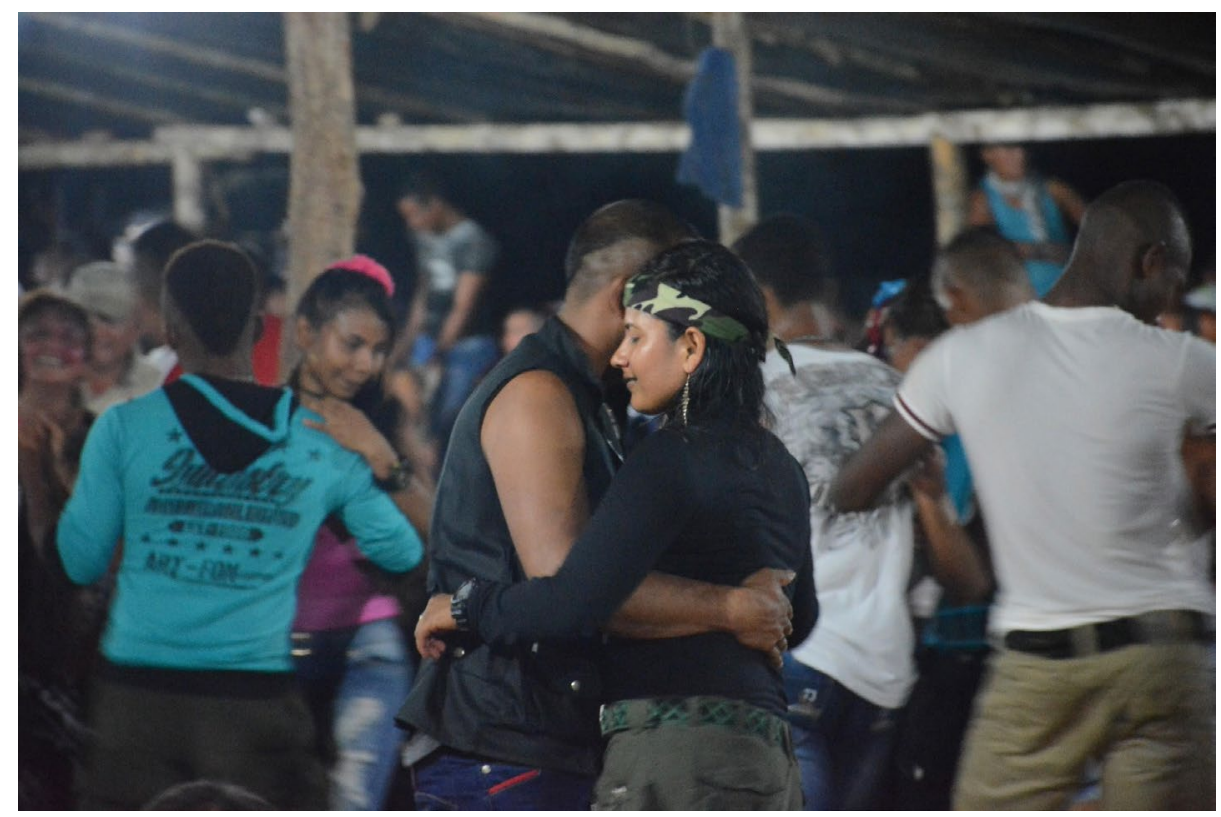

Fuente: [Fotografía de Diego Fajardo]. Colinas, Guaviare, 2017.

Fuente: archivo fotográfico personal. Espacio festivo. 


\section{La conmemoración como espacio festivo}

Los escenarios de conmemoración para las FARC-EP han sido espacios festivos. De hecho, durante la participación de la conmemoración se comentó de fiestas de dos o tres días al interior de la selva donde la guerrillerada organizaba baile, esparcimiento y celebración de su propia historia en medio del rigor del conflicto. La conmemoración del aniversario 53 no fue la excepción y las noches del 27 y 28 de mayo de 2017 estuvieron atravesadas por la música, la cerveza y el baile.

La primera noche de fiesta inició con la presentación de un grupo de reggaetón compuesto por dos artistas que hacían parte de la delegación de Arauca. Durante los dos días sonó salsa, reggaetón y música tropical. Lo que se evidenció fue que cuando sonaban ritmos como salsa o reggaetón la mayoría de "las farianas y los farianos" se sentaban, y las delegaciones de jóvenes de los entornos urbanos participaban activamente del baile; pero cuando sonaba una tanda de música tropical, cumbias y merengues ocurría lo contrario, masivamente las personas de la Zona Veredal ocupaban la pista de baile.

Durante los dos días los cancioneros farianos estuvieron dominados por la Sonora Dinamita, la SonoraTropical, Las Pica Pica, LosTupamaros y Rikarena, aunque no por ello puede decirse que sus gustos estén atravesados solo por lo tropical. De hecho, en una emisión de septiembre de 2010 del programa de noticias CM\& (https://www.youtube. $\mathrm{com} /$ watch? $\mathrm{v}=\mathrm{fhUyHJ} 3 \mathrm{~g} 3 \mathrm{tc}$ ), se presentó un video de una fiesta de las FARC-EP en la que se muestra al Mono Jojoy bailando música electrónica junto a una guerrillera joven, lo que indica que los géneros urbanos no necesariamente les eran ajenos. En este caso habría que atender seguramente a otros elementos para pensar dicha lógica, como la cuestión intergeneracional, o las disposiciones y aprendizajes de los cuerpos a la hora de bailar distintas músicas.

Por momentos, durante este momento festivo, las consignas entusiastas de las organizaciones estudiantiles y juveniles presentes se tomaban el espacio desplazando la música y asumiendo la centralidad de la experiencia festiva. En estas situaciones ocurría algo parecido con el reggaetón y la salsa; mientras los jóvenes de los entornos urbanos cantaban y la música paraba, "los y las farianas" veían. En ambos casos se manifestaban gustos, disposiciones corporales, geografías del goce y estéticas políticas particulares en relación con quienes participaban de la conmemoración.

Estas centralidades y periferias que por momentos asumieron los distintos sujetos y sus formas de ocupar el espacio, dan pistas sobre los sentidos de la conmemoración y a quienes principalmente estaba dirigido el espacio. Si bien la conmemoración era una celebración principalmente de "los y las farianas", su carácter público implicó que gran parte de los discursos e iniciativas que tuvieron allí lugar se dirigieran justamente a quienes no pertenecían a la guerrilla. 


\section{Jorge Briceño, el “Mono Jojoy”: periferia y centralidad en las memorias farianas}

Teniendo en cuenta que las personas concentradas en el ETCR de Colinas habían pertenecido al Bloque Oriental liderado por muchos años por Jorge Briceño, y que después de su muerte esta estructura asumió su nombre, uno de los elementos que más llamó la atención fue la poca presencia que tenía su figura en los registros que se presentaron en la conmemoración. Al revisar los dibujos, fotografías y composiciones que se contaron por varias decenas, la imagen de este referente escasamente apareció en dos de ellas.

La ausencia de imágenes contrasta con la enunciación constante por parte de las personas de la antigua Zona Veredal quienes se referían a él con "muestras de cariño". En una de las entrevistas adelantadas en este proceso de investigación una de las farianas señaló: "El Mono era ejemplar para el guerrillero. Él era... un tipo muy carismático” (Katherine, comunicación personal, 2017). Esta relación establecida con la "memoria de Jojoy" emerge con fuerza en las narrativas sobre su muerte y las situaciones límite por las que atravesaron quienes estuvieron en el fragor del combate:

Aparte de que matan al Mono siguen ahí, bombardeando,
amorteriando y ametrallando de todo. A parte de eso... dolor,
porque mucha gente lo vio. Inclusive se hicieron matar; las
muchachas que lo cuidaban a él prefirieron morirse allá dentro
con el Mono. Eso fue muy triste. Yo digo que uno de los peores
experimentos de Estados Unidos fue inventarse los bombarderos.
(Katherine, comunicación personal, 2017)

Estas referencias a Briceño como "guerrillero ejemplar" contrastan sobremanera con las subjetivaciones dominantes que sobre él circularon en medios masivos. Su figura fue definida en gran medida por la circulación de imágenes televisivas que mostraban las condiciones en las que eran retenidos militares y policías en el año 2000, donde Briceño exponía como única opción de libertad el canje por guerrilleros presos, mientras les señalaba a los secuestrados que debían “prepararse para largo tiempo”. A partir del uso de este tipo de imágenes, en su figura se concentraron en gran medida los sentidos que asociaban a las FARC-EP al secuestro, a la crueldad y a lo "monstruoso".

Si esta organización se caracterizó en el imaginario político oficial y en la opinión pública como terrorista, cruel y sin orientación política, convirtiéndose en "el principal enemigo" de la sociedad colombiana, Briceño fungió como el mal encarnado que participaba de su conducción. De hecho, la operación de bombardeo que resultó en su "abatimiento" fue nombrada con la metáfora religiosa de Operación Sodoma, asociándose al fuego divino que según la biblia arrasó con la "perversión”. 
Los matices ocasionales hechos sobre algunos comandantes de formación universitaria, como Alfonso Cano, intelectual/terrorista, no encajaban con el origen campesino y la crianza guerrillera de Briceño. Un artículo titulado “el 'Mono Jojoy' amaba el whisky, las camionetas y los caballos finos”, publicado en el diario El País de Cali después de su muerte, es una muestra del tipo de "subjetivaciones" que de manera dominante circularon sobre el:

El más sanguinario hombre de las Farc, verdugo infalible y de corazón estrecho ante las súplicas de secuestrados y guerrilleros condenados por su fusil, caía rendido a los pies de cualquier lujo con el que pudiera ostentar ese poder bárbaro que predicaba tener en la selva. Sus manos, por ejemplo, culpables de un número de asesinatos que nadie logra cuantificar, casi siempre permanecían arregladas con una manicura de tipo francés. "Jojoy”, animal de guerra célebre por su condición de tropero inhumano, mataba con las uñas pintadas. (El País, 2010)

Quizá la escasa presencia que se observó de la figura de Briceño en la conmemoración del 2017 tuvo que ver con la huella que dejó para muchos la presentación de este como un guerrero irracional. Limitar su presencia en el espacio conmemorativo se justificaba en tanto lo que se quería evidenciar era como las FARC le estaban apostando a nuclear su propio relato en torno a la paz y no a la guerra.

Una de las principales intenciones de este espacio fue dialogar con personas externas a las propias FARC-EP y, por lo mismo, era evidente el imaginario que se podía tener de Jorge Briceño. Su referencia simbólica era la que más difícilmente se acoplaba al carácter público de la conmemoración. Los organizadores del espacio quizá eran conscientes que la imagen de guerrillero "cruel” con la que los medios justificaron su muerte, no calzaría fácilmente con las narrativas de lucha armada y paz.

No obstante, esta descripción no constituye del todo un silencio en la conmemoración, pues en las entrevistas y conversaciones adelantadas emergió constantemente su figura, por lo que advertir su limitada presencia puede que se explique mejor como una enunciación periférica, un posicionamiento estratégico de las FARC-EP en relación con los sentidos socialmente dominantes que intentaron ser discutidos en la conmemoración.

La enunciación periférica de la figura de Briceño en la conmemoración número 53 en Colinas, contrasta, sin embargo, con el uso de su imagen en iniciativas de conmemoración adelantadas en mayo de 2018 por las disidencias FARC - EP (Bloque Oriental) en el departamento de Arauca. 


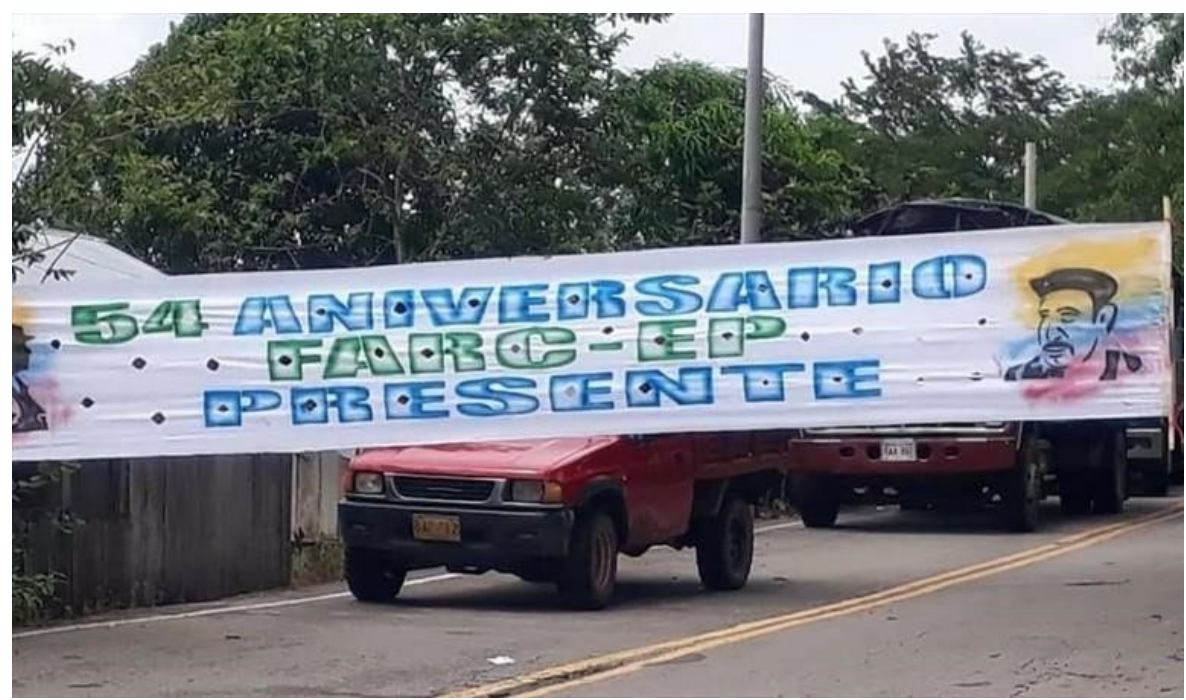

Ilustración 5. Disidencias de las FARC instalaron pancartas y bloquearon vías en Arauca. Fuente: RCN, 2018.

\section{Consideraciones finales}

Tanto en el Programa Agrario de los Guerrilleros como en los comunicados públicos de las conmemoraciones anteriores a septiembre de 2012, las FARC proclamaron y defendieron un relato sobre la paz, entretejido con su relato sobre la lucha armada. Las tensiones o contradicciones integradoras entre estos discursos deben leerse a la luz de las discrepancias y rupturas mismas que han aflorado al interior de la organización a lo largo de su historia. Precisamente un espacio como el de la conmemoración de su último aniversario en armas permiten entrever los sentidos de estas tensiones y contradicciones, así como las formas de gestionarlos.

Las FARC - EP afrontaron el espacio público de la conmemoración de 2017 siendo conscientes tanto los discursos que criticaban como "falsa" su disposición frente a la paz, así como las narrativas que de manera dominante los definían como una "organización terrorista”, con un origen perdido y sin un claro rumbo político.

En el escenario conmemorativo de Colinas, las FARC priorizó el diálogo con las personas ajenas a la zona veredal, ratificando su compromiso con los acuerdos firmados. Los artefactos de la memoria diseñados para este espacio, como las galerías o la maqueta, así como los espacios culturales, los discursos presentados y los comunicados públicos, fueron pensados de manera que lograran mostrar ante los otros su búsqueda histórica por la paz. 
Los dos días de conmemoración interpelaron los discursos guerreristas, así como a quienes no hacían parte de su organización y estaban presentes en la conmemoración. Esto implicó el uso de referentes simbólicos socialmente aceptables que permitieran una mayor circulación de las narrativas expuestas. Esto se evidenció, entre otros elementos, en el uso insistente de símbolos como la bandera y la paloma blanca, o el canto del himno de la paz y el himno de la alegría, de manera que se enmarcara la conmemoración a partir lo aceptado por la opinión pública. Lo anterior no quiere decir que se perdieran del radar otros elementos simbólicos que los acompañaron como organización insurgente, por ejemplo, el himno de la Internacional Comunista, o incluso la simbolización de las armas como referencia de la resistencia.

Finalmente, en la conmemoración puede evidenciarse el reto que la FARC ha tenido que sortear en su discurso público alrededor de referentes organizativos de peso en su historia, pero socialmente poco aceptables como es la figura de Jorge Briceño. Este caso permite perfilar la "difícil búsqueda de sentido" en torno a su pasado y su presente que tendrá que enfrentar esta organización.

\section{Referencias}

Alape, A. (1994). Tirofijo, los sueños y las montañas. Bogotá, Colombia: Editorial Planeta.

Arenas, J (2015). Diario de la resistencia de Marquetalia. Bogotá: Ediciones Izquierda Viva.

ACORE. (2017). Carta al Señor Presidente de la República. Recuperado de http://www.acore. org.co/boletin-acore/carta-al-senor-presidente-la-republica/.

Blair, E. (2011). Memoria y poder: (des)estatalizar las memorias y (des)centrar el poder del Estado. Universitas Humanística, 72, 63-87.

Bejarano, M. (16 de junio de 2017). El general Flórez metió la bota. Las dos orillas. Recuperado de https: / / www.las2orillas.co/general-florez-metio-la-bota/.

CEDEMA. (2010). 46 años de batallar por la nueva Colombia. Recuperado de http://cedema. org/ver.php?id=3945.

CEDEMA. (2011). 47 años de batallas por la paz desde la resistencia armada. Recuperado de http: / / cedema.org/ver.php?id=4477.

CEDEMA. (2012). FARC - EP 48 años de lucha armada rebelde. Recuperado de http: / / cedema. org/ver.php?id $=5013$.

CEDEMA. (2013). De Marquetalia a la Habana. 49 años de lucha por la paz. Recuperado de http: / / cedema.org/ver.php?id=5657.

CEDEMA. (2014). FARC-EP 1964 - 2014. Recuperado de http://cedema.org/ver. php?id $=6205$. 
CEDEMA. (2015). FARC - EP 51 años de lucha por la paz. Recuperado de http: / cedema.org/ ver.php?id=6769.

CEDEMA. (2016). FARC - EP 52 años de lucha por la paz de Colombia. Recuperado de http:// cedema.org $/$ ver.php?id $=7230$.

CEDEMA. (2017). FARC - EP 53 años de lucha por la paz. Recuperado de http://cedema.org/ ver.php?id $=7672$.

Disidencias de las FARC instalaron pancartas y bloquearon vías en Arauca. (23 de mayo de 2018). RCN Radio. Recuperado de https://www.rcnradio.com/colombia/llanos/ disidencias-de-las-farc-instalaron-pancartas-y-bloquearon-vias-en-arauca.

El "Mono Jojoy" amaba el whisky, las camionetas y los caballos finos. (23 de septiembre de 2010). El País. Recuperado de https://www.elpais.com.co/judicial/el-mono-jojoyamaba-el-whisky-las-camionetas-y-los-caballos-finos.html.

Ferro, J. G. y Uribe, G. (2002). El orden de la guerra, las FARC-EP: entre la organización y la política. Bogotá, Colombia: Pontificia Universidad Javeriana.

Jaramillo, J. (2014). Pasados y presentes de la Violencia en Colombia. Estudio sobre las Comisiones de Investigación (1958-2011). Bogotá, Colombia: Pontificia Universidad Javeriana

Jaramillo, J., Parrado, E. y Torres, J. (2017). Los trabajos de y con la(s) memoria(s) en Colombia (2005-2016). En S. V. Alvarado. (Eds), Las ciencias sociales en sus desplazamientos: nuevas epistemes y nuevos desafíos (pp. 119-146). Ciudad Autónoma de Buenos Aires, Argentina: CLACSO/Universidad de Manizales/CINDE/ Universidad Javeriana/ Instituto de Bioética/ Universidad Simón Bolívar/ARNA.

Jelin, E. (2001). Los trabajos de la memoria. Madrid, España: Siglo Veintiuno editores.

Jelin, E. (2002.). Conmemoraciones: disputas en las fechas infelices (Comp). Madrid, España: Siglo Veintiuno editores.

Karl, R. (2018). La Paz Olvidada: Políticos, letrados, campesinos y el surgimiento de las FARC en la formación de la Colombia Contemporánea. Bogotá, Colombia: Librería Lerner.

Medina, M. (1986). La Resistencia Campesina en el Sur del Tolima. En G. Sánchez. y R. Peñaranda. (Comps.), 1986. Pasado y presente de la Violencia en Colombia (pp. 269-295). Bogotá, Colombia: CEREC.

Portelli, A. (1989). ¿Historia oral? Historia y memoria: la muerte de Luigi Trastulli. Historia y fuente oral, 1, 5-32

Rufer, M. (2010). La nación en escenas. Memoria Pública y usos políticos del pasado. Ciudad de México, México: El Colegio de México. 
Sandoval, P. (2002). El olvido está lleno de memoria. Juventud universitaria y violencia política en el Perú: la matanza de estudiantes de La Cantuta (tesis de grado). Universidad Nacional Mayor de San Marcos, Lima, Perú.

Stern, S. (2000). De la memoria suelta a la memoria emblemática: hacia el recordar y olvidar como proceso histórico (Chile, 1973-1998). En M. Garcés., P. Milos., M. Olguín., J. Pinto., M. T. Rojas. \& M. Urrutia. (Comps), Memoria para un nuevo siglo. Chile, miradas a la segunda mitad del siglo XX (pp. 11-34). Santiago de Chile, Chile: LOM ediciones.

Uribe, M V. (2007). Salvo el poder todo es ilusión. Bogotá, Colombia: Pontificia Universidad Javeriana.

Marulanda, M. (2015). Cuadernos de Campaña. Bogotá, Colombia: Ediciones Izquierda Nueva. 